\title{
A Library Adventure: Comparing a Treasure Hunt with a Traditional Freshman Orientation Tour
}

\author{
Sandra Marcus and Sheila Beck
}

This study addresses finding the best means of introducing incoming freshmen to the library and the skills and concepts of information literacy. The results of a traditional librarian-led orientation tour are compared with those of a self-guided treasure hunt. As part of an Introduction to College Life course in a multicultural community college, students in classes selected randomly participated in the alternate forms of orientation. Identical questionnaires, completed by all participants, contained both a test of learning objectives and an attitude survey. Statistical analysis of the test results and highly positive feedback indicated an educational advantage in the self-guided tour, supporting active learning theories. The study also demonstrates the need for continuing experimentation, innovation, and creativity in orientation tour design, as well as the value of such introductory tours, enhancing both comfort level and skill in library use.

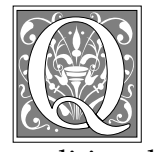
ueensborough Community College of the City University of New York is a multicultural commuter school with both traditional and nontraditional students. Of its approximately 10,000 students, 48.4 percent have part-time status. An average of 2,400 full-time students enter each year, with varying proportions having nonmatriculated status; approximately 27 percent begin in the spring semester. The Kurt R. Schmeller Library faculty, made up of seven full-time librarians and nine adjuncts, are noted for their student-centered patience and helpfulness. Students from four-year schools often travel to Queensborough to seek needed research assistance. However, attempts to address the need for library orientation has had a long and checkered history. A series of student workshops, accessible via signup sheets, was discontinued because of lack of participation. A Freshman Library Instruction Program, facilitated by teaching faculty collaboration, was discontinued because of lack of funds. Although the perception of student need for information literacy skills has prompted many teachers to increase "bibliographic instruction" class requests, some teachers still feel that they cannot afford to give up class time for a session in the library. There has never been a college or departmental course articulation policy regarding library instruction. Student participation in library classes is determined

Sandra Marcus is Assistant Professor and Coordinator of Reference Services and Information Literacy and Sheila Beck is Assistant Professor and Reference Librarian at Queensborough Community College; email:smarcus@qcc.cuny.edu, sbeck@qcc.cuny.edu. 
arbitrarily by teacher assignment in the English, speech, and basic skills departments. Consequently, in the past, many Queensborough Community College students were never introduced to either the library or the skills and tools of library research.

The college's counseling department, recognizing the importance of this deficiency, the critical significance of information literacy skills for all college freshmen, agreed to the chief librarian's suggestion that an introduction to the library be part of their four-session noncredit course, Introduction to College Life (ST 100). The course was extended to seven weekly sessions. The library component of one session, fifty minutes long, was a major achievement because all entering full-time matriculated students were required to participate in the program. Now these students would at least be exposed to the library.

\section{This model requires an education- ally sound, problem-solving ap- proach to learning.}

However, there were problems with this type of orientation. First, the students had no intrinsic need for library research, no motivation to pay attention to what they were being shown. If the counselor did not take attendance at the end of the session, some students would leave early. Although still valuable, the orientation session became a tour to show what the library contains, rather than a lesson in how to use it. At the information literacy coordinator's request, the counselors provided an assignment to motivate research. They asked the students to look for information about a future career in order to establish long-term goals for themselves. This was a good idea in theory but not very effective in practice. Because of the varying approaches of the individual counselors, the "assignments" were inconsistent and vague. And because there was no credit, there was no grade and no penalty for lack of attendance. Unfortunately, in the current educational milieu, a grade seems to provide both a primary motivation and a major measure of success, a crucial missing ingredient.

A second problem with this kind of orientation was the lack of time for handson experience. The resource-centered, active learning that expert pedagogical theorists deem so important to intellectual growth was missing from this exercise. ${ }^{1}$ Budget-induced cuts in adjunct hours introduced another difficulty into the situation-problems in meeting library responsibilities with a reduced staff.

It was at this point that one of the authors considered the possibility of another approach to the ST 100 library orientation tours (as they were now called). Lori Ricigliano at the University of Puget Sound described a treasure hunt orientation at a National LOEX (Library Orientation Exchange) Library Instruction Conference, published in Programs That Work. The goal for this program "was to provide a positive, welcoming, first experience with the campus library ... (for students) ...to become acquainted with the physical layout of the building and make them aware of the range and variety of information resources available." ${ }^{2}$ This mystery tour served as a model for the development of an interactive, selfguided treasure hunt form of orientation for the ST 100 classes.

The treasure hunt model leads the student through the library with a series of clues to a mystery. When the mystery is solved, participants receive some kind of prize or reward. Each clue leads to the discovery of a library resource at a station that provides the next clue. Ricigliano described several advantages to this model, and the authors found additional ones. ${ }^{3}$

First, there is motivation in the form of verbal or written praise with the location of each clue, as well as the reward for the solution. ${ }^{4}$

Second, this model requires an educationally sound, problem-solving approach to learning. The role-playing aspect of the project is a form of active learning strategy called simulation. ${ }^{5}$ It also presents the library in a less stodgy, more user-friendly light. 
Third, each student can move at his or her own pace and select a time for the exercise. This is an important advantage in an educationally diverse population with many nontraditional students.

Fourth, fewer librarians are required to conduct tours.

Fifth, it provides a degree of standardization in the orientation not possible in a traditional tour with the different approaches of both librarians and counselors.

Finally, this model should raise comfort levels in the use of the library because it requires students to approach several service desks and ask for help if they need it. Contact with diverse faculty and staff members who are pleasant and helpful should reduce any anxiety connected with library use in the future.

\section{Review of Literature}

In searching the literature, the authors sought information regarding the learning style that a treasure hunt tour represents, as well as background information on library orientation tours. They also studied the outcome goals of raising student comfort levels and lowering anxiety, and the educational objectives of library orientation, as well as evaluation techniques.

Aside from the Ricigliano program, which cited the adaptation of "Righteous Revenge" by the American Library Association, the authors could find little reported use of a treasure hunt model for academic library orientation. ${ }^{6}$ Moreover, the belief that hands-on activity guarantees learning was not supported by learning theorists. According to Robert Leamnson, "Hands-on activity ... can be of help in focusing attention, but it is not a sufficient cause for learning to take place." ${ }^{\prime 7}$

However, the authors discovered that theorists did strongly support hands-on activity in the presence of adequate motivation. "Students must become inspired ... to associate ... pleasurable, engaging activity with the content to be learned." ${ }^{\prime 8}$ An effectively devised treasure hunt tour should provide such motivation. The premise involves role-playing, a form of active learning called "simulation," which education theorists believe can "rekindle the enthusiasm for learning that some students have lost along the way and provide a welcome relief from much of higher education's prosaic everyday pursuits." 9

In addition, psychological studies have demonstrated the value of verbal and written reinforcement or praise as an important motivating factor in learning. ${ }^{10}$ Such reinforcement should occur at each station during a treasure hunt tour.

The search for library orientation literature produced a plethora of information. In general, researchers found tours to be a predominant method of introducing students to the library's physical plant, services, and personnel. ${ }^{11-14}$ However, in 1965, Barbara Phipps studied two hundred libraries and reached the conclusion that library tours are effective in orientating students to the physical plant and ineffective in teaching library use. ${ }^{15}$ She felt that students were not ready to learn library skills at the beginning of the semester when the tours were given. A. Carolyn Miller agreed with this assessment in 1980. She expressed the need for an effective method to instruct students in the use of research tools, imparting basic information skills and providing hands-on experience. ${ }^{16}$

Through the years, library literature has continued to address the issue of the best ways to accomplish different degrees of information literacy in an academic setting. However, the question has been clouded by a lack of standardized terminology. The terms "library tour" and "library orientation" are vague and usually interchangeable, not descriptive of whether there is a specific instructional component to the tour or simply a walk through the physical plant. Mary Jo Lynch, Michael Simons, and Lori Oling and Michelle Mach all discussed this difficulty. ${ }^{17-19}$ James Rice introduced a theoretical model in 1981. He divided library education programs into three levels: library orientation, library instruction, and bibliographic instruction. In his view, library orientation provides the student 
with an overview of the physical plant and introduces staff members, service departments, and library polices. It also should reduce library anxiety and motivate students to return to the library. Library instruction provides a more detailed discussion of library materials, and formal bibliographic instruction provides the highest level of training in research skills. $^{20,21}$

Although some librarians consider both this model and its first level out of date, the authors see this model as a useful means of defining terms in orientation descriptions..$^{22}$ Moreover, they believe level-one library orientation in the form of a library tour is essential for multicultural populations. Academic libraries are confusing places for students unaccustomed to them. There are computers, copy machines, microforms, reserve items, and reference and circulating books. The rules and services differ from those of school and public libraries, and the Library of Congress classification system differs from the Dewey system. Moreover, immigrants and international students may not be familiar with any library system. There also are language difficulties and cultural adjustments for some students. ${ }^{23}$ Part of the role of the academic librarian is the acclimation of students to the new library environment. These first-level user needs are too often ignored as librarians rush to teach bibliographic instruction. ${ }^{24}$

Although most librarians appear to feel that tours are the least effective means of orientation, this approach remains the most highly used. Data gathered by LOEX indicate that librarians feel the most effective methods of instruction are handson, individual instruction, and active learning, with lectures, tours of all types, printed handouts, and workbooks least effective. Yet, the same data show that 82 percent of the libraries surveyed offer tours and 94 percent offer lectures..$^{25}$ The authors believe that this discrepancy is most likely due to feasibility and college policy, rather than choice.

With budget crises reducing available staff, librarians have sought alternatives to the traditionally librarian-led tours to alleviate strain on personnel. Surprisingly, the treasure hunt format in an academic setting seems to have largely escaped notice. Some of the alternatives described in the literature are self-guided tours with printed materials and/or audiocassettes, slide presentations, videotapes, computer-assisted (CAI) presentations, and Web-based virtual tours. Although Web tours are new, none of the other alternatives have flourished. Traditional tours continue to dominate, although they are the most labor-intensive. ${ }^{26}$

One important objective of any type of orientation tour is that of raising the student comfort level. Pixey Anne Mosely conducted a survey of students at Texas A\&M during the 1995-1996 academic year to measure this outcome in a traditional tour format. Her results supported her hypothesis that "Though it may not teach indepth research skills, a guided tour service may be critical in making an overwhelmed freshman more comfortable entering the library or in orienting international students to the fundamental differences between American and many foreign libraries." ${ }^{27}$ Another advantage to librarian-led tours that she described is adaptability to serve a given audience and provide a personal touch. Her results "also substantiate the role of introductory orientations to the learning process." 28

More studies evaluating the effectiveness of orientation tours would be helpful. Most libraries report having no procedure for evaluating their choice of tours. ${ }^{29}$ One problem is the lack of quantitative rather than purely descriptive information. Simons suggested an approach to this issue. He recommended three ways to measure the impact of library tours; pretests and posttests on information reflecting educational objectives, student opinion surveys, and the measurement and evaluation of repeated questions at the reference desk. ${ }^{30}$ Although the authors found the use of a pretest unfeasible in the current study, they attempted to include a quantitative aspect to their tour 
evaluations by combining a posttest and a student opinion survey in a questionnaire. Overall, library literature indicates a need for more experimentation with alternative methods of academic library orientation.

\section{Methodology}

Because fewer students enter college in the spring, the authors determined that this would be the best time to initiate the treasure hunt tours. The seven counselors requested a total of twenty-six classes expressing their usual preference for the library session on the seventh and final week. The authors randomly selected half of these classes for the treasure hunt, including all counselors and all times of the day and week to ensure that the groups were comparable. In order to match the traditional tours as closely as possible, the authors chose the last two weeks of the ST 100 sessions for the self-guided tours. Students from designated classes received introductory sheets, directing them to the library circulation desk to begin their "library adventure" any time during the sixth and seventh weeks of the semester (appendix A). The rest of the classes were assigned dates and librarians for the traditional fifty-minute tour. Librarians and counselors received the same traditional orientation outline that was used in prior years, along with a memo explaining the new format used for half the students (appendix B).

The next step was to design the tour and write the scenario. Although the model involved solving a humorous, fictional murder, the authors decided that this would be inappropriate in a multicultural environment. The concept of a murder mystery as a party entertainment could be problematic to students from some cultural backgrounds. Instead, the mystery, called "Mission Quite Possible-A Library Adventure," would focus on locating a missing student. The clues would lead participants on the trail of the student to determine a careerdriven ultimate destination. Clues would be located at seven stations. There would be four manned stations; two unmanned shelf locations on the reference floor and in the circulating stacks; and two clues discovered via searches at a computer station. Faculty and staff at manned stations would receive introductory memos and exact directions, as well as sufficient clues and supplementary material (appendix C). The clue-containing folders on the shelves, situated adjacent to a sought book, would be clearly marked "Do not remove!"

The authors designed the clues with careful attention to educational objectives and with step-by-step directions for locating areas and using resources. The authors asked four work-study students to take the tour to test its difficulty and made content adjustments based on their suggestions. Expressions of praise and humor, photographs of library locations, copies of library material, and encouragement to ask for help accompanied each clue, as did a photograph and an explanation of the solution to the preceding clue. At the start of the tour, the circulation desk provided students with "credentials" for their mission: a Library Student Handbook and directions to use the OPAC, as well as ID card activation, necessary to use the library (appendix D). Students followed the clues (appendix E), proceeding from station to station, including all three floors. They moved from the circulation desk to the reserve desk (also used for media), to a reference shelf, to the periodicals desk and an article on microfilm, to a computer station with directions to both an EBSCO site (a book review) and the OPAC (locating the call number for the book), to a circulating book shelf, and finally to the reference desk. At the reference desk, the solution 
to the mystery awaited successful participants in a ready reference book on careers. The tour took thirty to forty-five minutes to complete.

In addition to an expression of congratulations, the authors felt the need for a more concrete reward, a primary reinforcement. They rewarded each winner with a piece of Hershey's solid chocolate, along with a Certificate of Achievement, designed as a diploma, with the date and student's name inscribed by the librarian covering the reference desk at the time (appendix F).

To evaluate and compare the two types of tours, the authors developed an eight-

\section{TABLE 1}

Educational Outcomes Questions 1 to 4

\begin{tabular}{|c|c|c|}
\hline \multicolumn{3}{|c|}{$\begin{array}{l}\text { Traditional Tour Educational Outcomes } \\
\text { Questions (1-4) }\end{array}$} \\
\hline Score & $\begin{array}{l}\text { Number } \\
\text { of Students }\end{array}$ & $\begin{array}{l}\text { Percent } \\
\text { of Students }\end{array}$ \\
\hline 0 & 3 & $4 \%$ \\
\hline 25 & 13 & $15 \%$ \\
\hline 50 & 34 & $42 \%$ \\
\hline 75 & 27 & $32 \%$ \\
\hline 100 & 7 & $8 \%$ \\
\hline
\end{tabular}

Total 84

Self-guided Tour Educational Outcomes Questions (1-4)

\begin{tabular}{lcc} 
Score & $\begin{array}{c}\text { Number } \\
\text { of Students }\end{array}$ & $\begin{array}{c}\text { Percent } \\
\text { of Students }\end{array}$ \\
\hline 0 & 4 & $3 \%$ \\
25 & 21 & $18 \%$ \\
50 & 35 & $29 \%$ \\
75 & 40 & $34 \%$ \\
100 & 19 & $16 \%$ \\
\hline
\end{tabular}

Total $\quad 119$

Percentage of Correct Answers

Correct Answers Traditional Self-guided

\begin{tabular}{rrr} 
& Tour & Tour \\
\hline 0 & 3.6 & 3.4 \\
1 & 15.5 & 17.6 \\
2 & 40.5 & 29.4 \\
3 & 32.1 & 33.6 \\
4 & 8.3 & 16.0 \\
\hline
\end{tabular}

item multiple-choice questionnaire for each participating student to complete (appendix $G$ ). The form was kept brief in order to overcome a perceived resistance to gratuitous surveys and tests. The first four items measured educational outcomes; the second four items gauged attitude. Because all students received identical questionnaires, the first four items evaluated only those learning objectives covered in both types of tours. Library skills that were presented to all treasure hunt participants, but may not have been introduced on all traditional tours, were not tested. These skills included locating books on the shelves and searching EBSCO and the

OPAC. The questionnaires were kept completely anonymous to dispel any apprehensive feelings associated with testing. At the start of the self-guided tour, each participant signed his or her name and that of his or her counselor in a dated record book at the circulation desk. The authors asked each traditional tour leader for the number of students present, along with the completed questionnaires. This information was valuable in determining the actual number of participants, as well as differences in counselor and librarian attitude. The follow-up procedure included an informal survey of the counselors, as well as the library faculty and staff for student feedback.

\section{Results and Analysis}

Completed questionnaires and student feedback provided the basis for evaluating the results of the tours. Although problems with both experimental design and execution weakened the study, analysis of the collected data and universally positive feedback from everyone involved provided evidence that the self-guided tours were highly effective. All of the counselors, even those initially resistant to the new format, requested that their classes be given the treasure hunt, rather than the traditional tour, the following semester. Results also suggested means of improvement. 


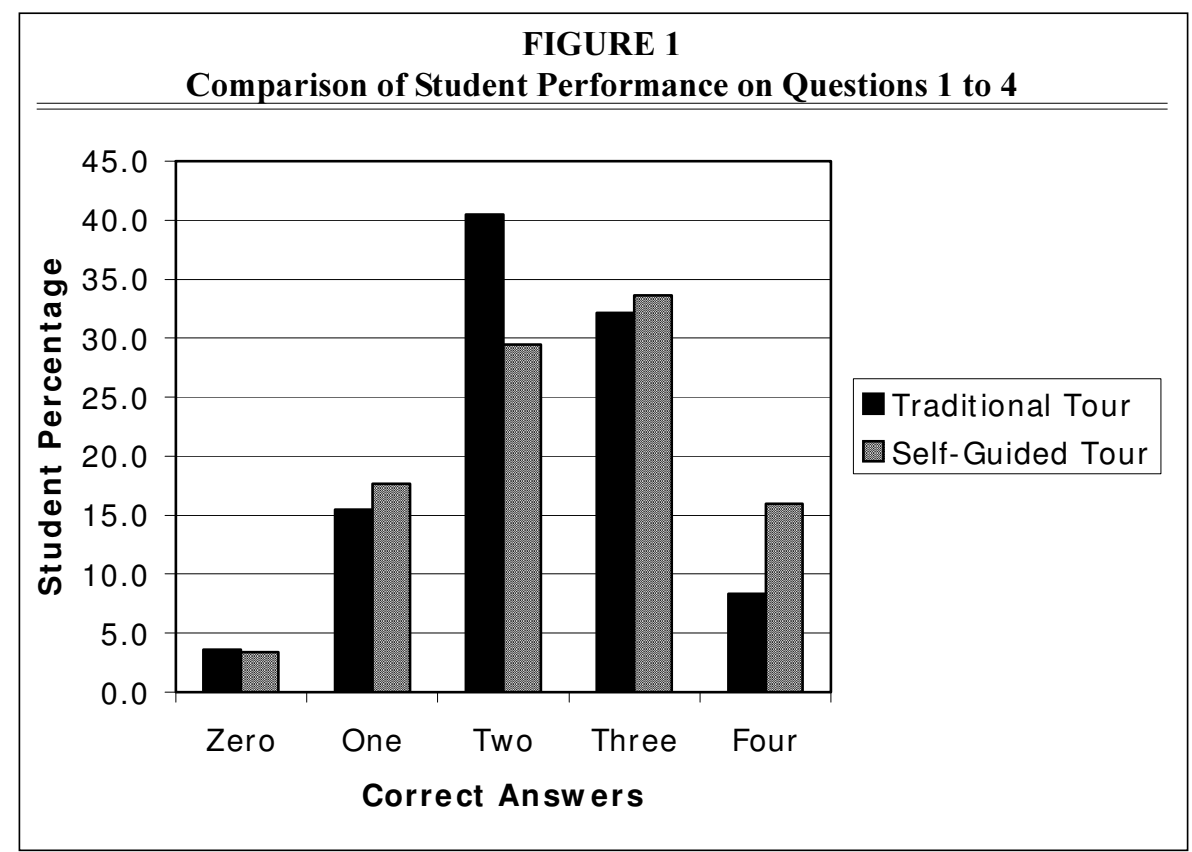

Although the sign-in sheet at the circulation desk contained 135 signatures, only 119 questionnaires were completed at the reference desk. This discrepancy could have been caused by busy librarians neglecting to give the questionnaires to some students or by students leaving the library without completing the tour. Some of the counselors required students to provide a certificate as proof of having taken a library tour; others had no requirements. Although the sign-in sheet asked for the name of the counselor, many students did not fill in this information. This problem could have been addressed by having a sign-out roster and emphasizing to the

\begin{tabular}{|l|l|l|l|l|}
\hline \multicolumn{1}{c}{ FIGURE 2 } \\
\hline Responses to Question 5: "The library staff..." \\
\hline $\begin{array}{l}\text { Are mean people who } \\
\text { interfere with your fun } \\
\text { Are disinterested but } \\
\text { answer questions }\end{array}$ & & & & \\
\hline
\end{tabular}




\begin{tabular}{|c|c|c|c|}
\hline & $\begin{array}{r}T \\
\text { Chi-sq } \\
\end{array}$ & $\begin{array}{l}\text { LE } 2 \\
\text { e Analysis }\end{array}$ & \\
\hline & Traditional Tour & Self-guided Tour & Total \\
\hline Observed & & & \\
\hline Perfect scores & 7 & 19 & 26 \\
\hline All other scores & 77 & 100 & 177 \\
\hline Total & 84 & 119 & 203 \\
\hline Expected & & & \\
\hline Perfect scores & $(26 * 84) / 203=10.8$ & $(26 * 119) / 203=15.2$ & 26 \\
\hline All other scores & $(177 * 84) / 203=73.2$ & $(177 * 119) / 203=103.8$ & 177 \\
\hline Total & 84 & 119 & 203 \\
\hline Name & Observed & Expected & Chi-square \\
\hline C1R1 & 7 & 10.8 & 1.337037037 \\
\hline C1R2 & 77 & 73.2 & 0.19726776 \\
\hline C2R1 & 19 & 15.2 & 0.95 \\
\hline $\mathrm{C} 2 \mathrm{R} 2$ & 100 & 103.8 & 0.13911368 \\
\hline Sum & & & 2.62 \\
\hline
\end{tabular}

counselors the importance of making the tour a requirement. Some leaders of the traditional tours also neglected to collect questionnaires from all students. Two traditional tour leaders at the start of the tour period did not turn in questionnaires or exact participant numbers. For subsequent tours, librarians were asked to require a completed questionnaire from each student as he or she left the classroom. This approach, which should have been used from the start, was effective; however, although approximately 120 students took the traditional tour, only 84 completed the questionnaire.

Despite the incompleteness of the data, the authors believe that the information they were able to obtain provides accurate indications. Consequently, the data were carefully analyzed. The eight questions were treated as two different measures.
Because the first four questions tested learning outcomes, the hypothesis was that treasure hunt participants would score higher on these questions because of active learning and motivation. The tradi-

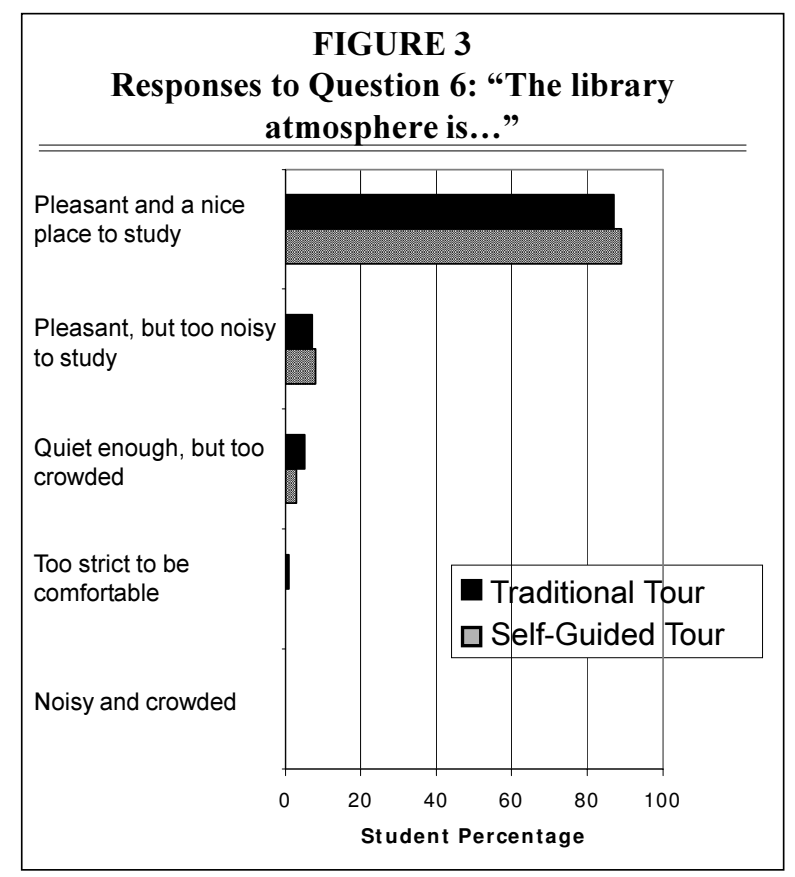


tional tour required mainly listening and following a librarian through the physical plant, with brief hands-on practice if time allowed.

In general, the students who took the self-guided tour did score higher on the first four questions. Fifty percent of the students on the self-guided tour answered at least three of the four questions correctly whereas only 40 percent of the students on the traditional tour achieved this result. Treasure hunt participants did consistently better on every question with the exception of question 3, which had equivalent results (table 1 and figure 1).
To determine whether there was a statistically significant difference in the performance of the two groups, a chi-square test was performed on the data. This test compares the observed data with what would be expected if the test scores were evenly spread out between the two tour groups. The greater the difference between the observed and expected data, the greater the likelihood that the null hypothesis, the hypothesis that the differences between the two groups were strictly due to chance, is incorrect. However, these data produced less than a 60 percent probability that the difference was

\begin{tabular}{|c|c|c|}
\hline \multicolumn{3}{|c|}{$\begin{array}{c}\text { TABLE } 3 \\
\text { Student Evaluation Questions } 5 \text { to } 8 \\
\end{array}$} \\
\hline $\begin{array}{l}\text { Question } 5 \\
\text { Choice }\end{array}$ & $\begin{array}{c}\text { Traditional } \\
\text { Tour }\end{array}$ & $\begin{array}{c}\text { Self-guided } \\
\text { Tour }\end{array}$ \\
\hline Really caring, enthusiastic, and very helpful & 52 & 68 \\
\hline Attentive and helpful & 37 & 26 \\
\hline Do their job & 10 & 6 \\
\hline Disinterested but answer questions & 0 & 0 \\
\hline Mean people who interfere with your fun & 1 & 0 \\
\hline Question 6 & Traditional & Self-guided \\
\hline Choice & Tour & Tour \\
\hline Pleasant and nice place to study & 87 & 89 \\
\hline Pleasant, but too noisy to study & 7 & 8 \\
\hline Quiet enough, but too crowded & 5 & 3 \\
\hline Too strict to be comfortable & 1 & 0 \\
\hline Noisy and crowded & 0 & 0 \\
\hline Question 7 & Traditional & Self-guided \\
\hline Choice & Tour & Tour \\
\hline Excellent & 42 & 50 \\
\hline Good & 52 & 45 \\
\hline Outdated, but usable & 4 & 4 \\
\hline Inadequate & 2 & 0 \\
\hline Terrible & 0 & 1 \\
\hline Question 8 & Traditional & Self-guided \\
\hline Choice & Tour & Tour \\
\hline Great & 31 & 38 \\
\hline Informative and interesting & 58 & 51 \\
\hline Informative, but dull & 8 & 3 \\
\hline Confusing & 1 & 5 \\
\hline A waste of time & 1 & 2 \\
\hline
\end{tabular}


not due to chance. (This statistical computation is available if readers want it.)

Nevertheless, a careful study of the observed and expected values indicated that the major difference between the two tour groups was in the greater number of perfect scores achieved by the self-guided group. The chi-square analysis was repeated, this time only comparing the number of students who scored 100 with those who did not. The result was the chisquare sum of 2.62. With one degree of freedom, this corresponds to around 90 percent confidence that the differences between the tours did, in fact, have an impact on the number of students who achieved perfect scores (table 2).

The second four questions addressed student attitude, asking for reactions to library staff, atmosphere, equipment, and the overall experience (table 3 and figures $2-5)$. The type of tour appeared to have little effect on the students' evaluation of the library environment. Most found the library staff very good: 94 percent for the students on the selfguided tour and 92 percent for the students on the traditional tour. The majority of students were pleased with the library atmosphere: 89 percent for the self-guided tour and 87 percent for the traditional tour. A minority of the students found the library noisy: 8 percent for the self-guided tour and 7 percent for the traditional tour. Most of the students found the library equipment satisfactory: 95 percent on the selfguided tour and 94 percent on the traditional tour. The majority of the students on both tours found the library experience informative and interesting.
More students on the self-guided tour found the library to be confusing: five percent to one percent. This could indicate a need to make the clues easier and a reluctance of some students to ask for help. On the other hand, eight percent of the students on the traditional tour found the library dull, compared to three percent of the treasure hunt participants.

\section{Discussion and Conclusions}

The value of orientation tours in general is evident from the extremely positive results of the attitude survey. Both comfort level and library skills seem to be enhanced in such tours. In addition, despite the weak statistical evidence, the authors believe that the superiority of the hands-on tour is indicated. They discovered that in this type of study there are many variables that cannot be controlled. The authors believe that the difference between learning on the tra-

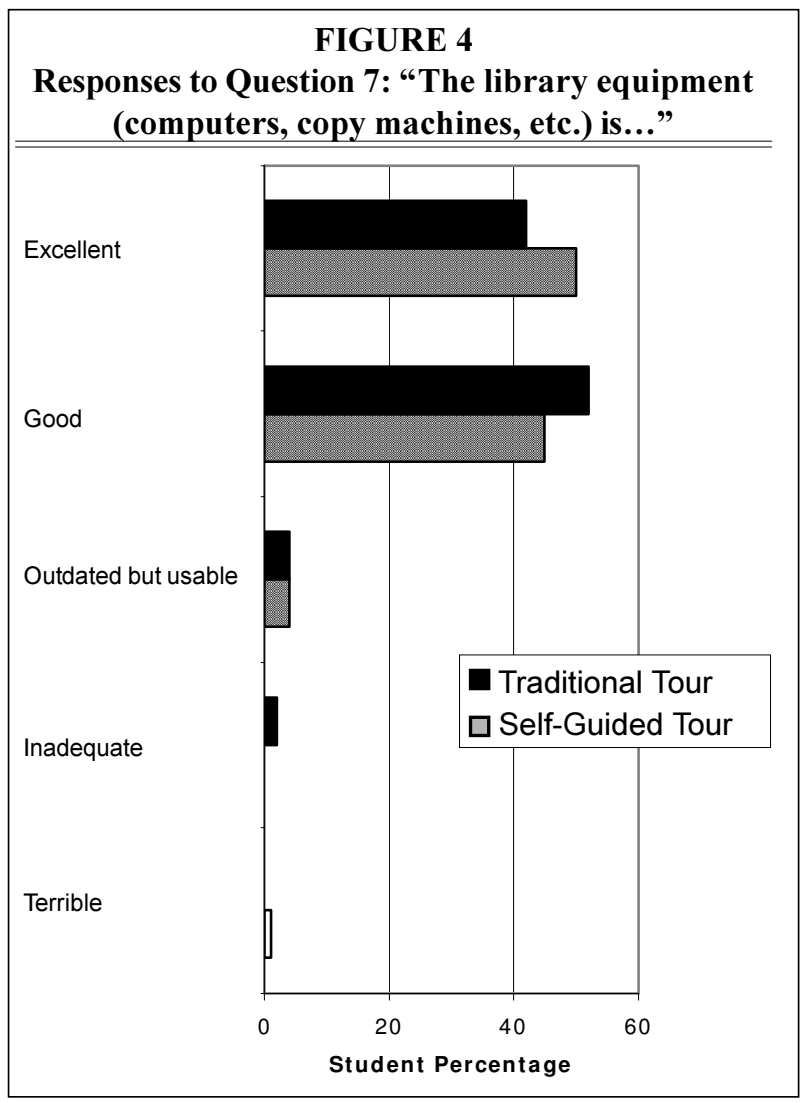


ditional tour and that of the treasure hunt was greater than the questionnaire results indicate. The questionnaire did not include objectives that were not always covered on the traditional tour but were on the treasure hunt, such as locating a book on the shelf and searching in different databases. In addition, librarian attitude was an important consideration that could not be addressed. It is highly likely that some librarians emphasized information that they saw on the questionnaire, although they were asked not to. An additional advantage of the self-guided tour is that all participants must have their ID cards activated. This step is necessary to use books and computers in the library, as well as to access licensed resources off campus. Although traditional tour participants are informed of the importance of activating their cards, it is not mandatory.

It is evident that more research is needed to determine the relative effectiveness of various formats of orientation tours. However, the authors plan to honor the requests of the counselors and focus next on refinement of the hands-on tour. The confusion of some students in locating a book from a book review on EBSCO was traced to mistaking the title of the article for that of the book. This difficulty, not identified by students doing the preliminary trials, was corrected by more explicit description in the clue. The fact that English is not the first language for many of the students must be taken into consideration in the wording of the clues. Another important concern is the fact that some students are hesitant to ask for help. This must be communicated to all library

\section{FIGURE 5}

to Question 8: "The library experience was..."

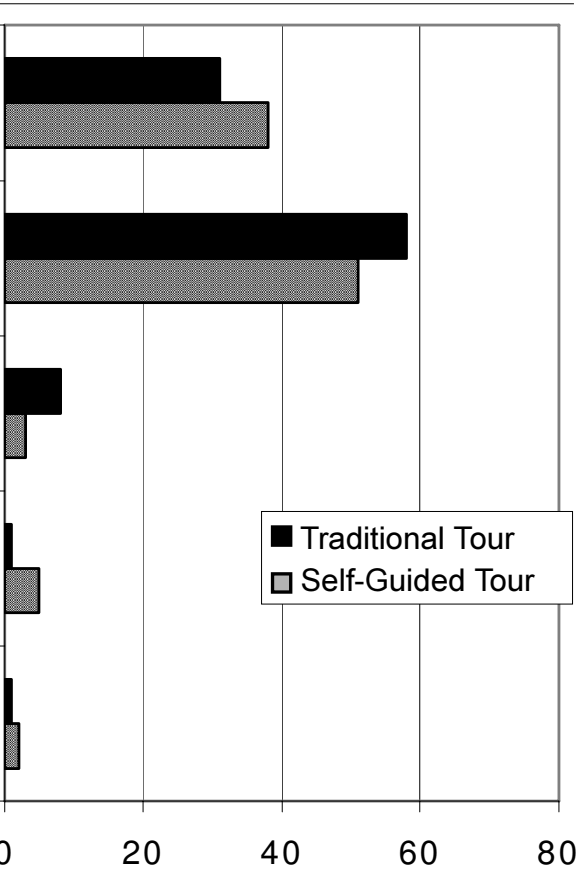

Student Percentage

faculty and staff members, who should offer unsolicited help to struggling students.

Timing also is significant in orientation tour effectiveness. The counselors' request that the traditional tours be offered during the seventh week of the semester was honored. And the hands-on tours were offered during the sixth and seventh weeks of the semester to make the timing equivalent for the study. However, the first few weeks of the semester are more appropriate for an orientation tour, as well as being a less busy time for the librarians. Beginning the tours during the second week of the semester, possible with the elimination of the traditional tour, should provide another improvement.

The need for experimentation, innovation, and creativity in orientation tour design, as well as in other forms of teaching, is a challenge that all educators must continue to face. 


\section{Notes}

1. Chet Meyers and Thomas B. Jones, Promoting Active Learning (San Francisco: Jossey-Bass, 1993).

2. Lori Ricigliano, "The Library Mystery Tour: A Freshman Orientation Program That Works," in Programs That Work: Papers and Sessions Materials Presented at the Twenty-Fourth National LOEX Library Instruction Conference held in Denton, Texas, 16 to 18 May 1996, ed. Linda Shirato (Ann Arbor, Mich.: Pierian Pr., 1997), 207.

3. Ibid.

4. Dawson R. Hancock, "Influencing Graduate Students' Classroom Achievement, Homework Habits and Motivation to Learn with Verbal Praise," Educational Research 44, no. 1 (spring 2002): 83-95.

5. Meyers and Jones, Promoting Active Learning, 89-119.

6. Ricigliano, "The Library Mystery Tour," 207.

7. Robert Leamnson, "Learning as Biological Brain Change," Change (Nov./Dec. 2000): 40.

8. Ibid.

9. Meyers and Jones, Promoting Active Learning, 89.

10. Hancock, "Influencing Graduate Students' Classroom Achievement, Homework Habits and Motivation to Learn with Verbal Praise."

11. Mary Jo Lynch, "Library Tours: The First Step," in Educating the Library User, ed. John Lubans Jr. (New York: R.R. Bowker, 1974), 255.

12. Mary Du Mont and Barbara F. Schloman, "The Evolution and Reaffirmation of a Library Orientation Program in an Academic Research Library," Reference Services Review 23, no.1 (spring 1995): 85.

13. Pixey Anne Mosley, "Assessing the Comfort Level Impact and Perceptual Value of Library Tours," Research Strategies 15 (winter 1997): 261-70.

14. Lynch, "Library Tours," 255.

15. Barbara H. Phipps, "Library Instruction for the Undergraduate," College and Research Libraries 29 (Sept 1968): 411-23

16. A. Carolyn Miller, "The Round Robin Library Tour," Journal of Academic Librarianship 6, no. 4 (Sept. 1980): 215.

17. Lynch, "Library Tours," 255.

18. Michael Simons, "Evaluation of Library Tours," EDRS, ED 331513 (1990): 2.

19. Lori Oling and Michelle Mach, "Tour Trends in Academic ARL Libraries," College and Research Libraries 63, no.1 (Jan. 2002): 21.

20. James Rice Jr., Teaching Library Use: A Guide for Library Instruction (Westport, Conn: Greenwood Pr., 1981).

21. Du Mont and Schloman, "The Evolution and Reaffirmation of a Library Orientation Program in an Academic Library," 85.

22. Ibid

23. Arthur Downing and Leo Robert Klein, "A Multilingual Virtual Tour for International Students," College and Research Libraries News 62, no.5 (May 2001): 500.

24. Ann Curry, "Seizing an Instructional and Marketing Opportunity: Audiocassette Tours in Public Libraries," Public Libraries Quarterly 16 no.2 (1997):7.

25. Linda Shirato and Joseph Badics, "Library Instruction in the 1990s: A Comparison with Trends in Two Earlier LOEX Surveys," Research Strategies 15 (winter 1997): 233-35.

26. Oling and Mach, "Tour Trends in Academic ARL Libraries," 21

27. Mosley, "Assessing the Comfort level Impact and Perceptual Value of Library Tours,"

28. Ibid., 269.

29. Oling and Mach, "Tour Trends in Academic ARL Libraries," 21.

30. Simons, "Evaluation of Library Tours," 3. 


\section{APPENDIX A \\ Introductory Flyer}

Attention Students:

As part of your Introduction to College Life class, you have been assigned a library adventure tour-"Mission Quite Possible," a self-guided treasure hunt to learn about the library.

The tour will take 30 to 40 minutes, and you will receive a certificate to show your counselor that you participated.

Your task will be to locate a missing student, Wanda B. Astar, by following her trail in a series of clues located throughout the library to figure out where she went, and why. (You will also learn how to use the library in the process.)

Your first stop is the checkout desk located at the entrance to the library. Report here with your CUNYCARD and say that you are a participant in the library adventure tour. You will receive your information packet and your first clue.

Good luck, and have fun! 


\section{APPENDIX B Traditional Tour Outline}

Half of these tours will be conducted with basically the same format as in the past; the other half will be self-guided treasure hunts. (Please see attached letter and flyers.) The brief hands-on session will continue to be held in L318, the Special Collections Center. All students should be asked to fill out a very brief questionnaire at the close of each session. The anonymity and nonevaluative function of these questionnaires should be emphasized.

Once again, the focus of the class is career information. Finding such material in every section of the library should be emphasized (ready reference, reference, circulating books, vocational guidance pamphlet files, etc.).

The hands-on session in L318 should include a career information search. Directions for DPAC, DPER, and INTERNET (including some appropriate sites) can be distributed at this time.

The revised Student Handbook should be distributed.

\section{Please encourage everyone to validate CUNYCARDS before leaving the library.}

Counselors and students should meet librarians at the second floor entrance to the library at the designated time. Sessions should begin as soon as everyone is assembled in order to maximize the time available. Students should be permitted to leave at fifty minutes past the hour, but invited to stay longer for hands-on practice if they have the time and inclination.

\section{The outline for the presentation follows:}

I. A welcome and brief description of the library with handbook distribution

II. A tour of the library physical plant and demonstration of resources, focusing on career information

A. Second floor - main or reference floor

1. Reference desk

a. Students will be encouraged to approach the reference desk. "Librarians at the reference desk are here to help. Don't be afraid to ask."

b. The difference between a reference book and a circulating book

c. Ready reference material (A number of good resources on vocational guidance are available here.)

d. Internet use

The need to purchase and format data disks in order to save Internet material.

e. Literature pamphlet files and card catalog

(1.) Reference material (criticism, Cliff Notes, etc.)

(2.) Circulating material (plays and short stories in collections)

2. Checkout counter and circulating book policy

a. There is a six-book limit. Books are checked out for three-week periods, with one renewal possible. Fines are levied on overdue books, as well as a suspension of all library privileges.

b. CUNYCARD ID gives access to other CUNY undergraduate school libraries. they leave today.

c. We recommend that students have their CUNYCARDs validated before 


\section{APPENDIX B Traditional Tour Outline (continued)}

3. Periodical desk and procedures, "What is a periodical?"

a. Call slips

b. Periodical catalog (Current Periodicals)

c. Microfilm (Ask for help in using reader/printers.)

4. Leisure reading area.

5. Copy machines (two on each floor) "Bring change or buy a five dollar card."

6. The TouchNet Kiosk and Parking Token Dispenser

a. A campus directory, with telephone numbers and a free phone to contact any college department

b. A printable campus map, as well as locations and pictures of any campus building

c. Parking tokens

7. The importance of allowing enough time to do research

C. First floor

1. Group study room

2. Reserve desk with books, articles, media, and computer start-up disks and keys; rules for use of reserve material, Internet computers, word processors, and printers

3. Internet room

4. Academic computing center should be pointed out. This is not part of the library; it is used for typing papers and other computer applications.

5. Silent study room

B. Third floor

1. Circulating books and how to locate with call no.

2. Pamphlet files - Social science, science, art, music, corporate annual reports, and vocational guidance (The vocational guidance file will be opened.)

3. A brief "hands-on" session will be held in L318. Both CUNY+ and Internet sources of career information will be presented. Instructional handouts will be available.

a. Reference books

b. CUNY+ (DPAC)

c. Internet and licensed resources 


\section{APPENDIX C \\ Faculty and Staff Treasure Hunt Directions}

\section{Checkout Desk}

When a participant comes to the desk, please follow these steps:

1. Ask for the CUNYCARD.

2. Make sure it is activated.

3. Give student the welcome sheet and clue h.

4. Give student the information packet:

student handbook,

DPAC directions,

periodical request slip,

and reserve material request card.

5. If asked, give directions to the first floor.

\section{Reserve Desk}

When a participant comes to the desk, he or she should give you a completed reserve request card for the Star Wars audio record album that has been set aside.

Please follow these steps:

1. Take the request card and place it in the envelope provided.

2. Show the student the record album

3. Give the student the clue sheet.

\section{Periodicals Desk}

When a participant comes to the desk, he or she should give you a completed periodicals request slip for the microfilm of Time magazine that has been set aside.

Please follow these steps:

1. Take the request slip and place it in the envelope provided.

2. Show the student the microfilm.

3. Give the student:

- the copy of the microfilm article;

- the clue sheets (clues 3, 4, and 5 stapled together).

\section{Reference Desk}

When a participant comes to the Desk, he or she should have completed the tour and be asking for motion picture careers information.

Please follow these steps:

1. Congratulate the student for completing the tour.

2. Show the student the careers book

3. Give the student the final page.

\section{The next steps are very important.}

4. Collect all the clues and put them in the box provided. (The student should keep only his or her DPAC directions, student handbook, and final sheet.)

5. Give the student a questionnaire to fill out, emphasizing that it is not a test and that his name does not go on it. Place the questionnaire in the folder provided.

6. Fill out the certificate with the date and the student's name. Sign it on the "reference librarian" line.

7. Congratulate the student again, give him the certificate, and a candy. 


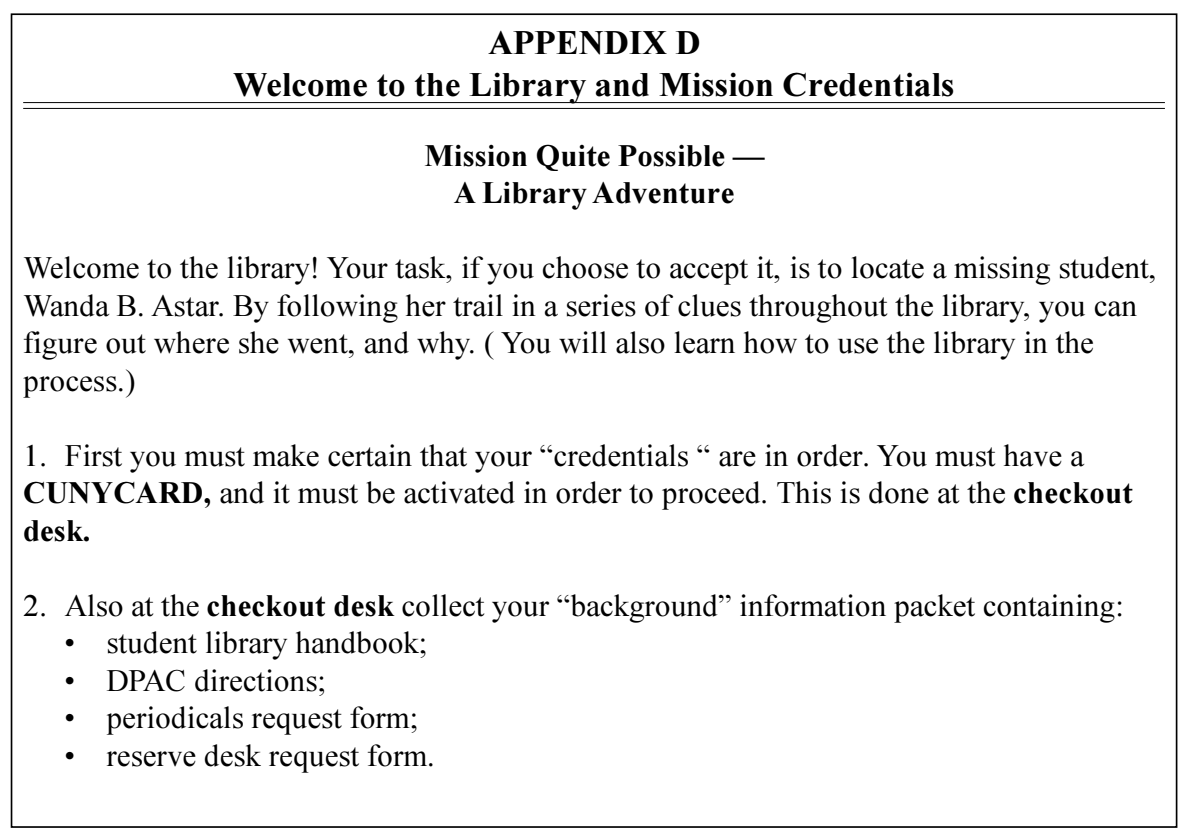




\section{APPENDIX E \\ Clues}

\section{Clue number 1}

Wanda was seen listening to a Star Wars audio record in the media center on the first floor, near the reserve desk. This may provide a valuable clue. To get the record you need the call number. Everything in the library is arranged by call number. The call number of the record is Queensborough Records 2390.

Fill out the reserve desk request form. (It is in your information packet.)

Include the call number.

You are on the $2^{\text {nd }}$ floor.

Go downstairs to the $1^{\text {st }}$ floor by going through the door next to the rest rooms. Turn right to the group study area. (If you turn left, you will be in the silent study area.)

Pass the Internet room on your left, and go up to the reserve desk on your right. (The academic computing center, where you may use word processors to type papers, is across the room.)

Give the request form and cunycard to the person at the reserve desk. (Students come to the reserve desk to use textbooks and the Internet room, as well as audio and video media.)

\section{Clue number 2}

Good work! You are on the right track!

The staff at the reserve desk remember Wanda asking about George Lucas, the writer and producer of Star Wars. They directed her to a reference book (a book that you REFER to, but don't take out of the library.) It is an encyclopedia about the lives of famous people called Current Biography.

Return to the second floor.

Reference books are on the second floor, arranged by call number. The numbers run from "A" to "Z," first by letter and then by number. The call number of Current Biography is

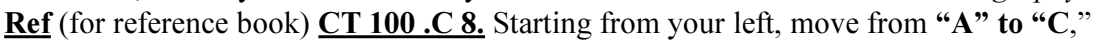
then "CA," "CB," "CC," until you get to "CT." Now move from "CT 1," "CT 2," until you get to "CT 100."

Current Biography is a set of green books with yearly volumes. George Lucas is in 1978 on page 257. There is a nice picture of him from that year.

Leave the book on the shelf for everyone else. We have copied the pages for you. Take the pages and the next clue from the folder in the book. Take only one copy!

\section{Clue number 3}

Great! You are on the trail!

Wanda not only used this book, but she did something she wasn't supposed to do- she marked it!

In the References section at the end of the article (a list of where the writers of the article got their information, their sources.), Wanda underlined Time 109:61 Mv 30'77 por (What do these strange symbols mean? You think about it and suddenly you understand.) 


\section{APPENDIX E \\ Clues (continued)}

Time is obviously a magazine. If you look in Current Periodicals, you notice that we have all the Time issues from 1938 to the present. But which issue of Time did Wanda look at? That must be what the other symbols refer to. My 30 ' 77 must mean May 30th, 1977. 61 must be the page number. That leaves 109 as the volume number. And por must stand for portrait; the article contains a picture of George Lucas.

Wanda looked at this article, and you must follow her steps if you are to find her.

To get a periodical article (A periodical is a newspaper, magazine, or journal; anything that is published at periodical intervals.), you must fill out a periodical call slip (find it among your documents).

Present the completed call slip, along with your CUNYCARD at the periodicals desk. (This desk is located on the $2^{\text {nd }}$ floor with the checkout counter, but at the other end. It is indicated by a big "Periodicals" sign.)

\section{Clue number 4}

Congratulations! You are a born detective! The people at the periodicals desk remember helping Wanda look at the article on microfilm. (Older magazines are kept on microfilm, rather than in their original paper format, to save space. They must be read on a special magnifying machine.) Wanda had some difficulties with the microfilm reader, located next to the periodicals desk.

To save time, we have copied the article so that you don't have to search for it. (But note what microfilm looks like, in case you have to use it in the future.)

The periodicals desk staff remember that Wanda was unhappy with the article. She complained that she wanted something more recent. She was directed to a computer and told to look for George Lucas on Ebsco (an online periodical index).

\section{See Clue number 5 for Ebsco directions}

\section{Clue number 5}

\section{Retrace Wanda's steps using the following Ebsco directions}

(Ask a librarian for help if you encounter problems.)

1. Sit down at any computer. (Go to the desktop by clicking on the little dash (-) button at the top of the screen, on the right side. Keep clicking until you get a blue-green screen with icons.)

2. Double click on the Netscape or Internet Explorer icon.

3. (If you find that you are at the QCC home page, click on Library on the upper left of the screen. ) From the Library Home page http://web.acc.qcc.cuny.edu/library/), click on Licensed Resources, located on the left.

4. From Licensed resources, click on Ebsco (the seventh yellow box from the top on the left).

5. Click the enter box at the top of the screen.

6. Type George Lucas and life (make sure you spell his name correctly) in the box at the top of the screen, next to find. (Wanda evidently wanted to know about his life.)

7. Click the search box.

8. Click on Full text of record number 1 ( Forecasts: Nonfiction)

9. This is a book review. It describes a book, a biography (life story) of George Lucas. (Wanda was heard to exclaim, "I have to get that book!") 


\section{APPENDIX E \\ Clues (continued)}

10. Write down the title of the book.

Continue to follow Wanda's trail with the directions in Clue 6.

Clue number 6

Follow Wanda's trail by using DPAC (the online catalog) to get the call number of the book and locating the book on the shelf of the $3^{\text {rd }}$ floor.

1. Go to the desktop of the computer again by clicking on the minimize button (the dash [-] at the upper right hand corner of the screen).

2. Double click on the cunyplus icon.

3. You should now be looking at the DPAC screen. (If not, ask for help from one of your friendly neighborhood librarians.) Follow the Searching for Books in DPAC directions (partially repeated here):

(1.) Type DPAC and hit the enter key

(2.) Type SET CAT QB (this limits your search to our library) and hit the enter key.

(3.) Type $\mathrm{K}=$ (the main word in the title of the book)

(4.) Four entries will come up. The book you want is number 2. Hit number 2 on the keyboard (do not use the mouse here) and hit the enter key.

(5.) Notice Location, Call number, and status near the bottom of the screen. The location is "stacks." This means that it is a "circulating "book. It can be checked out of the library and is located on the $3^{\text {rd }}$ floor.

(6.) Write down the call number.

Go up the stairs in the center of the room to the 3rd floor. The stacks are located in a straight row. $\mathbf{A}$ is on your left, $\mathbf{Z}$ is on your right, just like the reference books. Find the book with the call number.

\section{Clue number 7}

(Take only one copy. Leave the book on the shelf.)

Great work! What powers of deduction! If you are reading this, you were able to discover the name of the book on Ebsco, look it up in DPAC, and locate it on the shelf with the call number!

Wanda had checked the book out and left a note in it when she returned it. The note said:

"I know all about George Lucas and Star Wars now. I just have to find out about opportunities for careers in the movie industry. I'll ask at the ready reference desk. I think they have books on careers there."

Go back down to the second floor-to the reference desk, where you will find librarians who are there to help you.

Congratulations! Congratulations! Congratulations!

You have solved the mystery!

The reference librarian has a book on careers in the motion picture industry that Wanda had looked at. Wanda then said loudly that she was off to Hollywood to find George Lucas and try to get a part in the next Star Wars movie.

(She left a forwarding address in the careers book.) 


\section{Queensborough Community College}

...... of the City University of New York

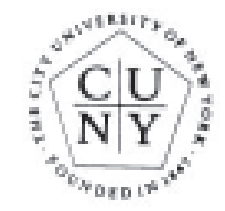

Certificate of Library Qualification

Be it known that on the

day of

, 2002,

completed the Kurt R. Schmeller Library Mission Quite Possible Tour and is awarded all the rights and privileges associated with said award. We applaud your mastery of the Library and its resources and hope that your hours spent in the Library are happy and productive.

Queensborough Community College The City University of $\mathcal{N}$ ew York
Reference Librarian 


\section{APPENDIX G \\ Tour Questionnaire}

1. On what floor is the silent study area?
(a) Basement
(b) First
(c) Second
(d) Third
(e) Roof

2. You go to the reserve desk for
(a) textbooks
(b) video tapes
(c) audio recordings
(d) Internet room
(e) all of the above

3. You go to the periodicals desk if you need
(a) an encyclopedia
(b) an almanac
(c) a magazine
(d) a textbook
(e) all of the above

4. An example of a reference book is
(a) a journal
(b) an encyclopedia
(c) a novel
(d) a textbook
(e) all of the above

5. The library staff
(a) are really caring, enthusiastic, and very helpful
(b) are attentive and helpful
(c) do their jobs
(d) are disinterested but answer questions
(e) are mean people who interfere with your fun

6. The library atmosphere is
(a) pleasant and a nice place to study
(b) pleasant, but too noisy to study
(c) quiet enough, but too crowded
(d) too strict to be comfortable
(e) noisy and crowded

7. The library equipment (computers, copy machines, etc.) is
(a) excellent
(b) good
(c) outdated, but usable
(d) inadequate
(e) terrible

8. This library experience was (choose 1)
(a) great (b) informative and interesting
(e) a waste of time
(c) informative, but dull
(d) confusing 